\title{
Risk Analysis of Lenovo Acquiring IBM PC Division
}

\author{
Jing Zhang \\ International Business School, \\ Yunnan University of Finance and Economics, Kunming, \\ 650221, P.R.China \\ 154128175@qq.com
}

\author{
Wenhua Yang* \\ International Business School \\ Yunnan University of Finance and Economics, \\ Kunming 650221, China \\ wenhuayoung@ynufe.edu.cn
}

\begin{abstract}
On 8 December 2004, when Lenovo announced its decision to acquire IBM PC Division, the IT industry and business community were shocked. It was a smaller Chinese company from a developing country that acquired a larger American company from the most industrialized economy in the world. Most people thought that this acquisition was destined to fail, and the acquisition was compared to 'a snake swallowing an elephant'. There are three types of risk -- employee risk, market risk and cultural integration risk associated with the acquisition. This paper analyses how Lenovo manages these risks.
\end{abstract}

Keywords-acquisition; employee risk; market risk; cultural integration risk

\section{INTRODUCTION}

Lenovo Group Limited was founded in 1984 in Beijing. Its original name of is Legend. Now it is the China's largest and the world's fourth largest personal computer manufacturer, ranking after Hewlett-Packard, Dell and Acer. In 2002, the Chinese government announced its 'global' policy by encouraging Chinese companies with the capabilities and know-how to expand abroad. At that time Lenovo controlled $30 \%$ share of the Chinese PC market, and it realized that the opportunity for further domestic expansion was limited. The acquisition of IBM's PC Division (PCD) is the most important step of Lenovo's global strategies.

In 1990s IBM adjusted its strategy and chose to focus on two main areas of business: software and service provision and profitability has been declining, even made a loss. In this context, IBM decided to sell its PCD. In 2004 IBM sold its PC group to Lenovo in a deal valued at $\$ 1.75$ billion and took a minority stake-approximately $18.9 \%$ in Lenovo [6]. However, the acquisition will definitely meet some challenges. This paper will discuss how Lenovo manages these challenges from the perspectives of employee risk, market risk and cultural integration risk respectively.

\section{EMPLOYEE RISK}

When IBM announced that it planned to sell its PC division to China's leading computer maker--Lenovo, employees from both companies were worried about their jobs. This decision caused panic among employees, since mergers often mean "pink slips". In addition, those former PC Division (PCD) employees might not be willing to work for a company whose major shareholders are Chinese, which might lead to employees lose their confidence, employees' loyalty,

\footnotetext{
*Corresponding author
}

motivation and commitment could be devastated. All of these could lead to potential "brain drain" [3].

According to Joyce et al. [7], "workers today expect their jobs themselves to be meaningful. They expect to participate in decisions, particularly those concerning the work they perform. They expect to know where the company is going and how it expects to get there. If management does not develop programs that satisfy those expectations, the company will not be successful in the long run." [7] The problem now is how Lenovo can retain the confidence of their employees and control the risk of losing talents.

\section{A. How will Lenovo Retain Employees}

Firstly, the new Lenovo would provide more career opportunities to top management which were limited under former IBM PCD. Lenovo emphasizes that they are not a traditional Chinese company with a rigid and closed mind, and "the culture of the new Lenovo is fully open and global" (Lenovo: an example of globalization of Chinese enterprises 2007). In the new Lenovo, about half of top management positions are occupied by Chinese and the other half of top management by former IBM PCD employees. The Chinese hold the positions of chairman of the board, chief financial officer, chief technology officer and chief of global supply chains. Steve Ward who had been the senior vice-president under IBM, served as CEO. Moreover, the official language of the new Lenovo is English, which sets the employees' minds at ease. Apart from this, the new Lenovo announces that there would be no changes to the compensation of former IBM employees, which controlled the risk of brain drain [6].

\section{B. Most People Applaud This Deal}

In fact, some industry analysts and academics applaud this deal, and believe that this merger probably means staff or even none staff reductions from both companies. David Lewin, professor of management at UCLA's Anderson School of Business says that "I do not think the workforce will be affected. If it were a domestic sale, like when Hewlett-Packard acquired Compaq, I'd say yes. By contrast, the IBM-Lenovo deal 'synergizes strengths', which citing IBM's expertise in personal computers-a low-margin area Big Blue has moved away from-and Lenovo's dominant market presence in China." Most IBM employees in the United States are in the areas of sales, marketing and research. Lewin does not predict staff changes there either. He pointed out that almost all of the personal computers are sold online; they have people for 
service, but not many for actual sales. So there would be no need to add or cut sales staff at either company. In addition, Joe Zhang, a stock analyst with UBS Investment Research in Hong Kong also mentioned that jobs at Lenovo or IBM would not be cut, given the tremendous growth opportunities in the merger deal [3].

In addition, before Steve Ward was appointed as Lenovo president and CEO, he headed PCD. He hesitated to tell his fellow IBM employees that their division had been sold out. Ward expected a backlash.To his surprise, he received applause and cheers from his employees. Ward attributes the unexpected reaction to the employees' passion for the PC. According to Musthaler [10], "in recent years, IBM did its best to stifle that passion by de-emphasizing PCs and making PCD feel like the unwanted stepchild. Lenovo's adoption of this stepchild meant that PCD would gain a prominent position in a growing company focused on the PC platform." Ward says that "less than a handful of employees declined the offer to trade an IBM badge for a Lenovo badge" [10].

No one can predict future, but the brain drain would not be the main barrier to the development of Lenovo and the Lenovo also would do its best to control the risk of losing talents.

\section{MARKET RISK ANALYSIS}

When it comes to market risk, the problem facing the new Lenovo is that whether people are willing to buy a high-priced product made by a Chinese company. In other words, would the new company lose their clients and customers forever? If Lenovo quickly loses the market share, it will be the first sign of business declining. One challenge is history: Mergers in the technology industry traditionally stumble. Hewlett-Packard (HP) became the No. 1 PC maker after it bought Compaq in 2002, but HP could only hold the position for a few months. Why? Dell took advantage of "FUD," or fear, uncertainty and doubt, among HP and Compaq customers, to gain market share. In fact, some observers alike that Lenovo's biggest challenge will be fending off Dell, which has made significant inroads in China and manufactures there to eliminate the cost advantages of its homegrown rivals. "The real issue here is whether Lenovo can be competitive with Dell," says Marshall Meyer, a Wharton management professor who has studied Chinese companies and traveled extensively in the country (The IBM/Lenovo Deal: Victory for China? 2005).

Meyer, like other users of IBM's ThinkPad laptops, says Lenovo's ability to maintain quality and innovation for notebook computers will be a key to the merged company's success. "The biggest selling point of IBM laptops is the warranty and service," says Meyer. "I wonder what the feelings will be about IBM if service is squeezed ... The ability to retain market share in the U.S. will depend on the ability to maintain the quality and warranty of the product." (The IBM/Lenovo Deal: Victory for China? 2005)

Meanwhile, the pressure to keep IBM customers satisfied was already mounting. In a research note, Gartner analysts stated that Lenovo "must retain the status of IBM's notebooks while developing a range of desktops that can challenge Dell's" (The IBM/Lenovo Deal: Victory for China? 2005). The first goal, they added, should be to keep the IBM core business in enterprise notebooks and use the IBM brand in other geographies to grow volume business.

Can Lenovo acquire the third largest PC business in the world -- behind Dell and HP -- and become a dominant player? Obviously, for Lenovo's top management, the answer is 'yes.' They planned to take some actions to reduce the market risks. They would keep the brand name intact by using the IBM logo on Think products for the next five years; they would retain the sales team of the former PCD, and send out over 2,000 people to the customers to reassure them that the new company would provide the same quality products and level of service; and they would establish the headquarters in New York - this would gradually be relocated to Raleigh, North Carolina.

30 April 2007 marked the second anniversary of Lenovo Group's purchase of IBM's PC Division (PCD). As part of the deal's terms, Lenovo relies on IBM Global Services (IGS) and IBM Global Finance (IGF) to fulfill commitments to enterprise customers. The IBM sales account teams remain a key distribution channel for Lenovo outside of China.

By the end of the first two years, Lenovo Group has realized many of its original goals, including integrating two disparate cultures in the newly formed company, maintaining the Think brand image for quality and innovation, and improving supply chain and manufacturing efficiencies, while keeping competitive pricing. However, Lenovo failed to meet a key objective of the merger: leveraging the combined strength of the two companies to grow volume and market share [4].

Instead, Lenovo has stagnated, with little growth. While 1Q07 - the strongest quarter outside of China in two years after the acquisition — showed year-on-year unit shipment and share gains, Lenovo still dropped to fourth place in the PC market as Acer rose to the third place. The main challenge for Lenovo remains the same--generating demand through more aggressive sales teams, improved channel strategy, increased market spending and better execution outside of China [4].

The IBM sales account teams wrote orders for new Lenovo products but could not actively increase new business. The Lenovo sales team had to improve its prospecting skills to gain new business. Meanwhile, the marketing team must solidify its message regarding Lenovo's identity so that prospective customers know "who the company is."

In 2005 when IBM's PCD was acquired, Lenovo failed to take advantage of the channel opportunities provided by HP's disarray. Since then, HP has completely reinvigorated its worldwide channel strategy during which the time that Acer was becoming a strong channel player in the U.S. In both regions, Lenovo was still trying to create the channel partnerships and programs to expand growth. Since it would take 12-18 months for channel programs to take into effect, this highlighted a serious problem [4].

Lenovo targeted Brazil, Eastern Europe and India as key growth markets during the IBM PCD acquisition. However, execution has been poor due to weak local channel partnerships. Marketing has been imaginative but underfunded and therefore, less effective than it might have been. In 2007, 
Lenovo announced a reorganization to move nearly 750 jobs out to emerging markets to improve local operations and reduce costs [4].

Despite all of these challenges, Lenovo remains as a strong global supplier and is able to provide quality products and services at competitive prices worldwide.

\section{CULTURE INTEGRATION RisK}

"Differences in practices and ways of thinking -- call them 'cultural' if you wish - are more persistent than top managers in corporations typically initially acknowledge," said Janne Tienari, a merger expert at Finland's Lappeenranta University of Technology. "Differences trigger surprises in social interaction. Surprises may turn out problematic, if not adequately addressed," (Culture challenge as Lenovo takes over IBM's PC business 2004).

Lenovo and IBM's corporate culture are different. Because Chinese government is one of important sponsor and shareholder of Lenovo, hierarchy culture is deeply embedded in the organization. Lenovo is a much formalized and structured place to work. Maintaining a smooth-running organization is important. Stability is the most important thing in Lenovo; every employee should strictly follow the company's policy, either in business or research area. Hierarchical behaviors are features of the daily work. In addition, Confucianism and Confucius's ideologies are the core values of most Chinese employees, even in IT companies like Lenovo. On the other hand, IBM's corporate culture is a Clan culture; IBM aims to provide a very friendly working environment, where people share a lot. Leaders are seen as mentors and coaches. People are held together by loyalty and tradition, commitment is high in IBM. IBM place emphasis a long-term benefits of human resources development, cohesion and high morale. Success is defined in terms of sensitivity to customers and concern for people. A premium is placed on teamwork, participation and consensus.

How Lenovo intergates cultural difference after the Merger of IBM is other tough challenge, "It's hard to bring two corporate cultures together in any merger, let alone one between an obscure Chinese computer maker and the struggling PC division of an iconic American brand".(Yang, 2007). For example, on Lenovo's routine meetings, Chinese employees don't like talking openly and directly to each other. They avoid direct communication model. American employees are quite different. They like direct communication style. The big differences in communication style results in many misunderstanding and inefficient meeting (Fusion 2007).

In order to eliminate some negative effects in cross-culture, Lenovo announced three guiding principles: candor, respect and compromise. Those principles are designed to unite the employees from two cultural backgrounds both national and corporate.

\section{A. Candor}

Chinese people understate or convey meanings indirectly. They use vague terms and double negatives. The Chinese never criticize others directly. Direct disagreement with the leader is avoided. So Lenovo launched an "Executive Expressions" course to help Chinese managers learn how to put their message across their colleagues. The importance of open and direct communication at meetings, not afterwards, is constantly emphasized. Speaking English is also an important way to learn candor. Lenovo understand that to thrive in a multinational company they have to speak English". Yang Yuanqing, Lenovo's chairman, has progressed from broken English to fluent English in less than two years, giving presentations and cracking jokes in his adopted tongue [5].

\section{B. Respect}

Respect for each other is always the baseline in any merger case. IBM grants their employees the flexibility regarding how they arrange their working hours. A variety of working hour options enables IBM's employees to combine their professional and private lives in an individually optimal manner. Employees have a high degree of autonomy regarding their working hours. Depending on the demand of the task, the nature of one's role and other obvious constraints, employees are free to determine when they start and end their working day. Part-time employment and working from home is also available. Before merger, Lenovo employees had to abide by the company's timetable and must stay at the office. Every employee is full-time employment. After meager, IBM's original work environment is retained. Lenovo keeps the previous IBM's employees' working style, but in China, the old policy is still working.

\section{Compromise}

Lenovo tries to satisfy IBM's requirement. For example, the location of the corporate head office remains the same. At first, Lenovo wanted dual head offices in order to avoid potential issues from the Chinese government, such as taxation. Stephen Ward, from IBM, insisted on retaining the head office in USA. In the end, Lenovo conceded by relocating its head office to New York.

Another example is compensation. IBM had a fixed salary policy, but Lenovo had low fixed salaries with bonuses related with the performance. After negotiations, Lenovo announced that there would be no change to the compensation of former IBM employees. "If we didn't compromise, there would be conflicts where no progress could be made and it might even lead to destructive factions to two different nationalities within the company" Said Liu Chuanzhi that, the chairman of Lenovo (Lenovo: an example of globalization of Chinese enterprises 2007).

After almost three years, the culture integration between IBM and Lenovo looked successful with no big culture integration conflicts. But still, Lenovo hasn't realized its marketing target, which means that the culture integration is not that perfect. Culture integration is a long-term process. Lenovo still needs to work hard in the following years.

\section{CONCLUSION}

Globalization is an irresistible trend, and the acquisition strategy can help companies enter a new market quickly. 
However, few benefits are achieved without some degree of risk. In this case, Lenovo is facing three main risks-employee risk, market risk and cultural integration risk associated with the acquisition. Lenovo also did a lot of work to solve these problems. Firstly it provided more career opportunities to top management which were limited under former IBM PCD and announced that there would be no changes to the compensation of former IBM employees to maintain employees' confidence and loyalty. Secondly it applied three guiding principles--candor, respect and compromise --in the acquisition to unite the employees from different cultural backgrounds and eliminate cultural conflict as a result. Finally Lenovo took some measures to reduce the market risk: it kept the brand name intact by using the IBM logo on Think products and retained the sales team of the former PCD to reassure the customers that the new company would provide the same quality products and the same level of service. This acquisition happened ten years ago, but people can still gain rich experience from this case.

\section{REFERENCES}

[1] J. Ackerly \& M. Larsson, The Emergence of a Global PC Giant: Lenovo's Acquisition of IBM's PC Division. Retrieved October 6, 2008,

[2] Culture challenge as Lenovo takes over IBM's PC business 2004. Retrieved October 6, 2008.

[3] D. Dowling, 'PC compatibility: IBM, Lenovo staffs mesh', vol. 84, no.1, pg. 15-16.2005.

[4] L. Fiering, Two Years After IBM PCD Deal, Lenovo Still Faces Challenges. Retrieved October 6, 2008,

[5] Fusion, B 2007, Work environment. Retrieved October 6, 2008.

[6] G.S. John, \& K. Michael, IBM sells PC group to Lenovo. W. Joyce, N. Nohria, \& B. Roberson, What really works - the $4+2$ formula for sustained business success, New York,2004.

[7] M. Lee, Lenovo net profit dives to US\$5 million. Retrieved October 6, 2008

[8] Lenovo: an example of globalization of Chinese enterprises 2007.

[9] L. Musthaler, Reconsidering the IBM-Lenovo deal. 2005.

[10] The IBM/Lenovo Deal: Victory for China? 2005

[11] Yang J 2007, 'Making Mergers Work', Business Source Premier, vol. 156 , no. 11 , pp.70. 